Portland State University

PDXScholar

\title{
Agent-Based Model Simulating Pedestrian Behavioral Response to Environmental Structural Changes
}

Amy Lobben

University of Oregon

Christopher Bone

University of Oregon

Follow this and additional works at: https://pdxscholar.library.pdx.edu/trec_reports

Part of the Urban Studies and Planning Commons

Let us know how access to this document benefits you.

\section{Recommended Citation}

Lobben, A. \& Bone C. Agent-Based Model Simulating Pedestrian Behavioral Response to Environmental Structural Changes. NITC-RR-696. Portland, OR: Transportation Research and Education Center (TREC), 2016. https://doi.org/10.15760/trec.142

This Report is brought to you for free and open access. It has been accepted for inclusion in TREC Final Reports by an authorized administrator of PDXScholar. Please contact us if we can make this document more accessible: pdxscholar@pdx.edu. 


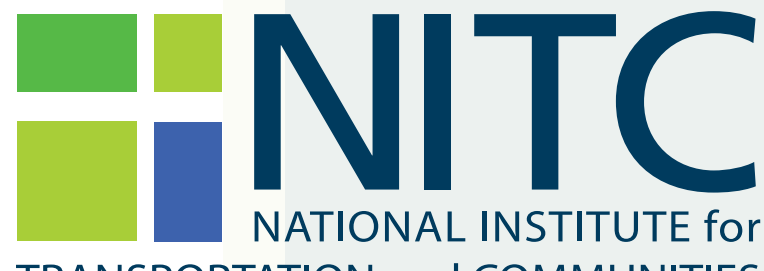

TRANSPORTATION and COMMUNITIES

FINAL REPORT

Agent-Based Model Simulating Pedestrian Behavioral Response to Environmental Structural Changes

NITC-RR-696 June 2016

NITC is the U.S. Department of Transportation's national university transportation center for livable communities.

\#": TREC 


\section{Agent-Based Model Simulating Pedestrian Behavioral Response to Environmental Structural Changes Final Report \\ NITC-RR-696 \\ by \\ Amy Lobben \\ Christopher Bone \\ University of Oregon}

for

National Institute for Transportation and Communities (NITC)

P.O. Box 751

Portland, OR 97207
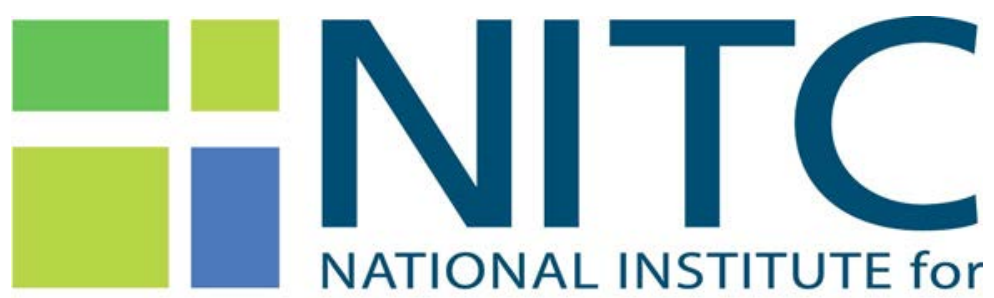

TRANSPORTATION and COMMUNITIES

June 2016 



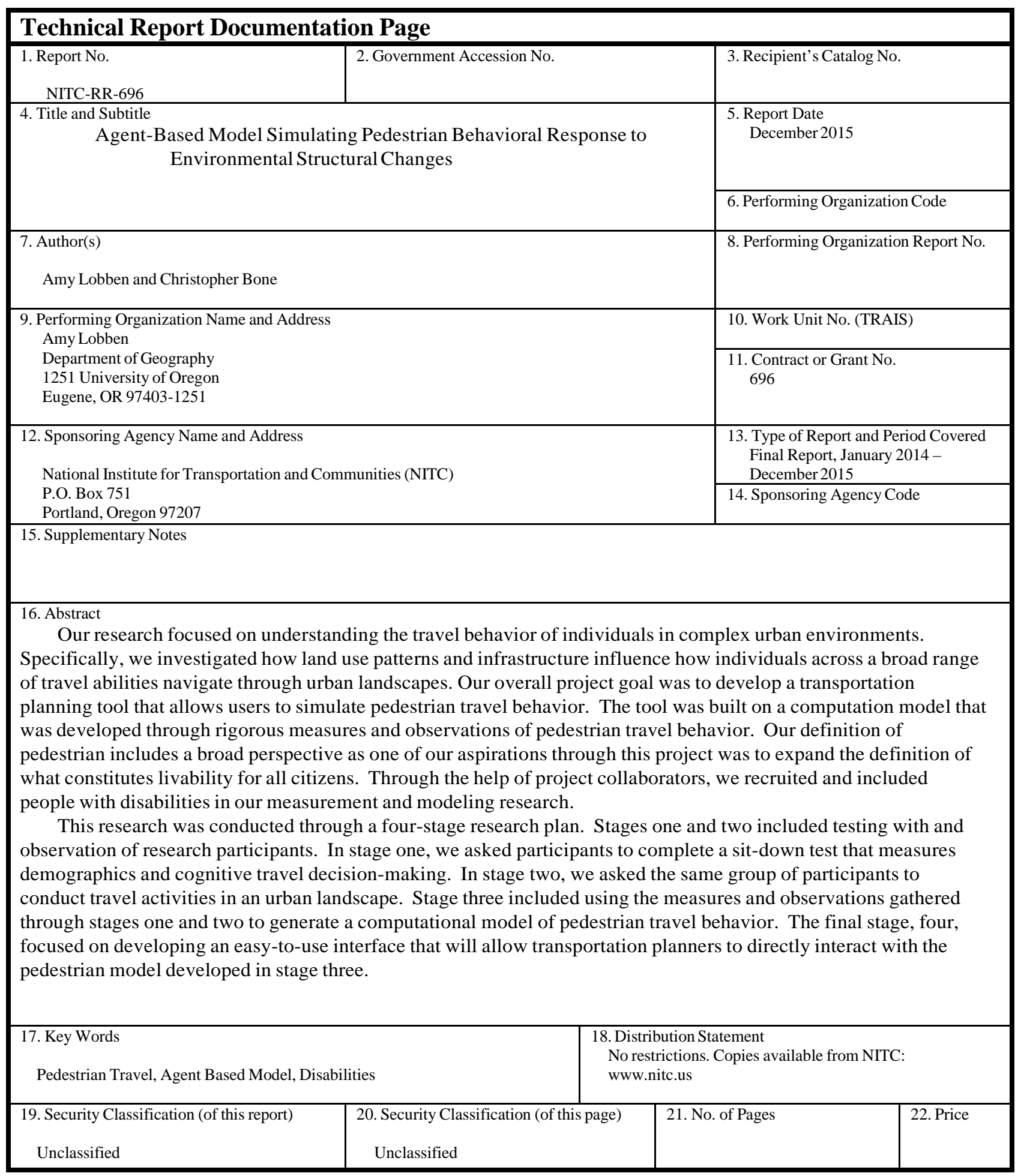




\section{ACKNOWLEDGEMENTS}

This project was funded by the National Institute for Transportation and Communities (NITC).

\section{DISCLAIMER}

The contents of this report reflect the views of the authors, who are solely responsible for the facts and the accuracy of the material and information presented herein. This document is disseminated under the sponsorship of the U.S. Department of Transportation University Transportation Centers Program in the interest of information exchange. The U.S. Government assumes no liability for the contents or use thereof. The contents do not necessarily reflect the official views of the U.S. Government. This report does not constitute a standard, specification, or regulation. 


\section{TABLE OF CONTENTS}

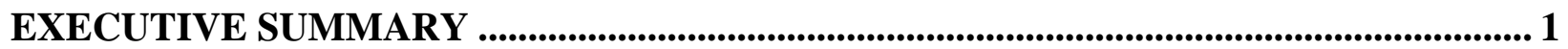

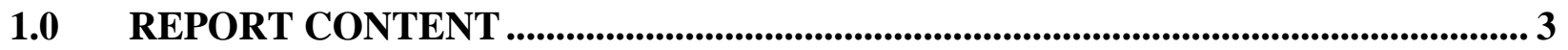

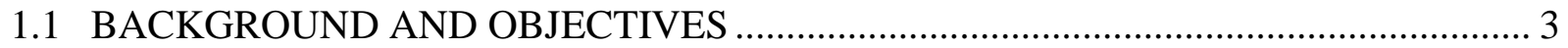

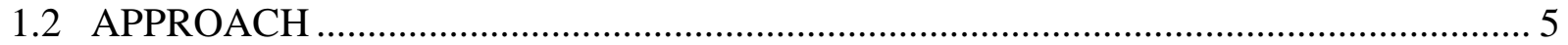

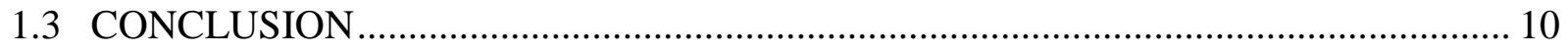

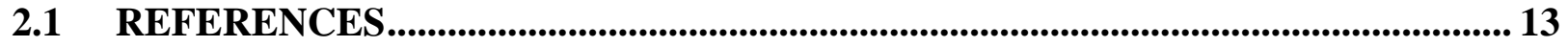

\section{LIST OF TABLES}

Table 1: Cognitive Variables and ABM Parameterization.....................................5

Table 2: Empirical Measures............................................................

\section{LIST OF FIGURES}

Figure 1: Example of model interface ................................................................................ 7

Figure 2: Examples of sidewalk characteristics......................................9 



\section{EXECUTIVE SUMMARY}

Several types of travel activities exist, and the differences between them are based on more than discrete trip objectives. Consider transportation concepts such as the mode of transportation, human sensory input channels, and the type of travel aid (i.e., GPS, in-car navigation system, maps, wandering, etc.) as only three noteworthy differences. In this research, we focused specifically on pedestrian travel behavior across a broad demographic, including people with disabilities. While pedestrian travel is one in which nearly everyone engages, the abilities, tasks and strategies associated with travel differ between people (Guo et al., 2013; Bernhardt, 2007; Allen et al., 1999; Montello et al., 1999) and between populations (Morton and Yousuf, 2011). While nearly everyone, at some point, faces travel stress, traveling efficiency can be profoundly affected by disabilities. And, with our aging population, the number of motor impairments and the number of newly diagnosed cases of blindness is growing disproportionately to the total population (www.nfb.org; www.afb.org). As a result, our society will be increasingly confronted with more and more citizens who face mobility challenges that affect their ability to travel efficiently and effectively within both their own and new environments (Morton and Yousuf, 2011). Without the ability to travel self-sufficiently, people lose the capability to get to work, school, the store, or social and cultural events, which results in loss of access to employment, health care, education, and cultural institutions.

Our research project combined both behavioral geography and agent-based modeling (ABM). Our overall objective was to advance our understanding and develop a computation model representing the relationship between pedestrian decision-making behavior and the complex urban environment. Three research questions drove the project design:

1. What is the relationship between pedestrian cognitive strategies, demographics, and their observed travel behavior?

2. How does the built environment affect pedestrian travel behavior?

3. How can we translate the laboratory test measures and environmental observations into a predictive and interactive model for use by transportation and planning professionals as well as researchers and educators?

Those research questions translated into three specific project objectives:

Objective 1: Sit-Down Measures of Pedestrian Travel Behavior. We developed a series of sit-down tests designed to measure pedestrian travel behavior. These tests were delivered in our lab on campus. They generated quantitative data that were then used to create the computational model in Objective 3.

Objective 2: Observed Pedestrian Travel Behavior. With the same participants from Objective 1, we observed actual pedestrian travel behavior. While sit-down tests can measure variables such as demographics and cognitive-choice, a robust research project should include observations of pedestrians conducting planned travel activities. So, we asked participants to travel between given locations in the urban landscape and we recorded their behavior. 
Objective 3: Agent-based Modeling. We developed two computational models utilizing an $\mathrm{ABM}$ approach. The purpose of an ABM is to simulate how individual behavior is influenced by the environment, both the physical space and the actions of other individuals (Abbas, 2012; Bernhardt, 2007). Behavior is encoded into the model by parameterizing each agent with decision-making capabilities from which a specific action can be taken in response to some environmental signal. Agents are autonomous, meaning that they have a specific goal that drives their behavior. ABMs are dynamic as agents can receive either discrete or continuous signals from the environment and respond accordingly over time. These qualities make ABMs suitable for simulating pedestrian travel behavior because agents can possess the goal of traveling through a spatial environment (Tilahun and Levinson, 2013; Guo et al., 2013; Avineri, 2012; Abbas, 2012; Bernhardt, 2007; Dia, 2002, Shi et al., 2005).

In each of our ABMs, computational agents represent individual travellers. These agents were parameterized using the collective results gathered with Objectives 1 and 2. In doing so, we were able to use the models to simulate how travel choices dictate individual navigation through an urban landscape. We simulated changes to travel parameters and observed the effect on overall travel with individual pedestrian agents, pedestrian agent classes (i.e., efficient travelers versus non-efficient travelers), and the entire pedestrian/agent population as a whole. These simulations identify variables that are vulnerable to pedestrian travel behavior. In other words, through parameter and environmental manipulation, the model can identify the variables that most and least affect pedestrian travel behavior. Our models simulated travel behavior of people without disabilities and the other included people with disabilities. Another key difference between the two models is the focus of interaction. In other words, one model allows the user (i.e., a city planner) to control agent cognition and observe the changes in agent travel behavior. The other model allows the user to control the environment and observe changes in agent travel behavior. These two control differences are assigned to the model without people with disabilities and the model with people with disabilities, respectively. 


\subsection{REPORT CONTENT}

\subsection{BACKGROUND AND OBJECTIVES}

Several types of travel activities exist, and the differences between them are based on more than discrete trip objectives. Consider transportation concepts such as the mode of transportation, human sensory input channels, and the type of travel aid (i.e., GPS, in-car navigation system, maps, wandering, etc.) as only three noteworthy differences. In this research, we focused specifically on pedestrian travel behavior across a broad demographic, including people with disabilities.

While pedestrian travel is one in which nearly everyone engages, the abilities, tasks and strategies associated with travel differ between people (Guo et al., 2013; Bernhardt, 2007; Allen et al., 1999; Montello et al., 1999) and between populations (Morton and Yousuf, 2011). Behavioral geographers and environmental psychologists provide much of the empirical findings in the area of pedestrian travel and map use. But, much of the research focuses on discrete laboratory measures without linking those measures to actual pedestrian travel behavior. In addition, challenges remain in understanding how travel is impacted by individual abilities. While nearly everyone, at some point, faces travel stress, traveling efficiency can be profoundly affected by disabilities. And, with our aging population, the number of motor impairments and the number of newly diagnosed cases of blindness is growing disproportionately to the total population (www.nfb.org; www.afb.org). As a result, our society will be increasingly confronted with more and more citizens who face mobility challenges that affect their ability to travel efficiently and effectively within both their own and new environments (Morton and Yousuf, 2011). Without the ability to travel self-sufficiently, people lose the capability to get to work, school, the store, or social and cultural events, which results in loss of access to employment, health care, education, and cultural institutions.

Because we know that real travel behavior deviates from rational choice theories (Avineri and Prashker, 2005), a modeling approach that parameterizes each traveler with unique behaviors represents a robust and realistic representation of travel behavior (Guo et al., 2013; Bernhardt, 2007). With needs, cognitive decision making-processes, access, and overall travel behavior varying substantially across populations, agent-based modeling (ABM) provides an ideal vehicle for analyzing and representing individual and across-population travel behavior (Avineri, 2012). ABM has practical and direct applications in transportation, especially in route-choice travel behavior (Dia, 2002; Shi et al., 2005). In fact, Abbas (2012) strongly argues that ABM is "the only modeling technique that can simultaneously take into account the attributes and constraints imposed by geography of roadways, the impacts of continually evolving social networks, and the changes from individual decision making and learning in transportation modeling (p.58).” 
The purpose of an ABM is to simulate how individual behavior is influenced by the environment, both the physical space and the actions of other individuals (Abbas, 2012; Bernhardt, 2007). Behavior is encoded into the model by parameterizing each agent with decision-making capabilities from which a specific action can be taken in response to some environmental signal. Agents are autonomous, meaning that they have a specific goal that drives their behavior. ABMs are dynamic as agents can receive either discrete or continuous signals from the environment and respond accordingly over time. These qualities make ABMs suitable for simulating pedestrian travel behavior because agents can possess the goal of traveling through a spatial environment (Tilahun and Levinson, 2013; Guo et al., 2013; Avineri, 2012; Abbas, 2012; Bernhardt, 2007; Dia, 2002, Shi et al., 2005). Also, agents, like people traveling in the real world, can be subjected to a variety of simulated environmental signals such as traffic patterns, traffic signals, obstacles and spatial constraints. Finally, an ABM can simulate how individuals influence the patterns emerging from the overall urban landscape and, conversely, how the landscape influences the travel behavior of individuals.

Our research project combined both behavioral geography and agent-based modeling. Our overall objective was to advance our understanding and develop a computation model representing the relationship between pedestrian decision-making behavior and the complex urban environment. Three research questions drove the project design:

4. What is the relationship between pedestrian cognitive strategies, demographics, and their observed travel behavior?

5. How does the built environment affect pedestrian travel behavior?

6. How can we translate the laboratory test measures and environmental observations into a predictive and interactive model for use by transportation and planning professionals as well as researchers and educators?

Those research questions translated into three specific project objectives:

Objective 1: Sit-Down Measures of Pedestrian Travel Behavior. We developed a series of sit-down tests designed to measure pedestrian travel behavior. These tests were delivered in our lab on campus. They generated quantitative data that were then used to create the computational model in Objective 3.

Objective 2: Observed Pedestrian Travel Behavior. With the same participants from Objective 1 , we observed actual pedestrian travel behavior. While sit-down tests can measure variables such as demographics and cognitive-choice, a robust research project should include observations of pedestrians conducting planned travel activities. So, we asked participants to travel between given locations in the urban landscape and we recorded their behavior.

Objective 3: Agent-based Modeling. We developed two computational models utilizing an ABM approach. In each model, computational agents represent individual travellers. These agents were parameterized using the collective results gathered with Objectives 1 and 2. In doing so, we were able to use the models to simulate how travel choices dictate individual navigation through an urban landscape. We simulated changes to travel parameters and observed the effect on overall travel with individual pedestrian agents, pedestrian agent classes (i.e., efficient travelers versus non-efficient travelers), and the entire pedestrian/agent population as a whole. These simulations identify variables that are vulnerable to pedestrian travel behavior. In other words, through parameter and environmental manipulation, the model can identify the variables that most and least affect pedestrian travel behavior. Our models simulated travel 
behavior of people without disabilities and the other included people with disabilities. Another key difference between the two models is the focus of interaction. In other words, one model allows the user (i.e., a city planner) to control agent cognition and observe the changes in agent travel behavior. The other model allows the user to control the environment and observe changes in agent travel behavior. These two control differences are assigned to the model without people with disabilities and the model with people with disabilities, respectively.

\subsection{APPROACH}

During the course of the NITC project, we had the goal of developing two different but closely related ABMs to be used as virtual laboratories to simulate how changes to agent cognition or the built urban environment influences pedestrian travel behavior. The first model uses agent behavioral variables related specifically to environmental cognition. Through an extensive literature review, we identified five cognitive variables, which are used to parameterize agent cognition of the model environment. Initial design of the cognitive model relies on data generated from five psychometric tests to evaluate the environmental cognition of the participants.

Each psychometric test targets a specific cognitive ability and generates the data used to parameterize agent cognitive variables in the model. In turn, each cognitive variable is reflected in a specific model output of agent behavior. This allows us to validate agent behavior within the model against real-world observed field behaviors. After agent parameterization and model simulations, an analysis between model outputs and in-field measures are used to validate the behavior of agents. Table 1 below outlines each cognitive variable and the related psychometric test, in-field measures and model output.

\begin{tabular}{|c|c|c|c|}
\hline Cognitive Variable & Psychometric Test & In-Field Measure & Model Output \\
\hline Spatial memory & Sense of direction test & $\begin{array}{l}\text { Sense of direction } \\
\text { measure }\end{array}$ & $\begin{array}{l}\text { Agent knowledge of } \\
\text { local environment }\end{array}$ \\
\hline $\begin{array}{l}\text { Non-metric location } \\
\text { coding }\end{array}$ & Self-location test & Self-location measure & Agent searching \\
\hline $\begin{array}{l}\text { Metric location } \\
\text { coding }\end{array}$ & $\begin{array}{l}\text { Environmental } \\
\text { perspective test }\end{array}$ & $\begin{array}{l}\text { Environmental } \\
\text { perspective measure }\end{array}$ & $\begin{array}{l}\text { Agent knowledge of } \\
\text { global environment }\end{array}$ \\
\hline Path integration & Place recognition & $\begin{array}{l}\text { Place recognition } \\
\text { measure }\end{array}$ & $\begin{array}{l}\text { Agent direct path } \\
\text { movement }\end{array}$ \\
\hline $\begin{array}{l}\text { Spatial reference } \\
\text { frame }\end{array}$ & Route strategy test & $\begin{array}{l}\text { Route strategy } \\
\text { measure }\end{array}$ & $\begin{array}{l}\text { Agent spatial } \\
\text { reference frame }\end{array}$ \\
\hline
\end{tabular}

Table 1: Cognitive Variables and ABM Parameterization

To gather the data to parameterize the model, 15 participants were recruited to complete a series of psychometric tests on spatial cognition and perform a series of associated in-field behavioral measures on the University of Oregon campus. The data generated for each test was transformed into a standardized index for each cognitive variable and applied directly to the ABM framework. Agent behavior is then recorded and correlated with the in-field behaviors for each participant, validating that the behavior of the agents in the model sufficiently represents 
real-world individuals. Table 2 below provides a detailed description of the variables, lab test, field test, and agent behaviors.

Emergent Behavior - Agent Route Choice - agents determine a best individual route through the environment from the interactions of route choice, establishing and maintaining orientation during movement, place recognition, location updating, spatial memory, and environmental knowledge acquisition.

Confounding variables - Environmental Familiarity - ability to construct/ maintain cognitive map of environment.

\begin{tabular}{|c|c|c|c|}
\hline $\begin{array}{l}\text { Cognitive } \\
\text { Variable }\end{array}$ & Lab Test & Field Test & Agent Behaviors \\
\hline $\begin{array}{l}\text { Sense of } \\
\text { Direction }\end{array}$ & $\begin{array}{l}\text { SBSOD scale } \\
\text { Self reported } \\
\text { measure. } \\
\text { Likert Scale }\end{array}$ & $\begin{array}{l}\text { EnvironmentalSOD } \\
\text { Participants indicate the } \\
\text { direction to } 12 \text { common } \\
\text { campus landmarks from two } \\
\text { separate locations. }\end{array}$ & $\begin{array}{l}\text { Spatial Memory - agent } \\
\text { ability to remember the } \\
\text { location of objects in the } \\
\text { environment. }\end{array}$ \\
\hline $\begin{array}{l}\text { Environmental } \\
\text { Perspective }\end{array}$ & $\begin{array}{l}\text { Spatial Orientation } \\
\text { Test } \\
\text { Participants locate } \\
\text { the direction to an } \\
\text { object based on the } \\
\text { arrangement of other } \\
\text { objects on paper. } \\
\text { Accuracy of Angle } \\
\text { measured. }\end{array}$ & $\begin{array}{l}\text { Environmental Orientation } \\
\text { Participants are asked to } \\
\text { indicate the direction to } 12 \\
\text { different common campus } \\
\text { landmarks from } 12 \text { hypothetical } \\
\text { positions. }\end{array}$ & $\begin{array}{l}\text { Euclidean location coding } \\
\text { - “Objective” or allocentric } \\
\text { perspective. Global } \\
\text { updating of the } \\
\text { environmental frame of } \\
\text { reference. }\end{array}$ \\
\hline Self-Location & $\begin{array}{l}\text { Self Location } \\
\text { Computer Test } \\
\text { Participants move } \\
\text { between egocentric } \\
\text { and allocentric } \\
\text { perspectives, finding } \\
\text { a location and } \\
\text { direction of } \\
\text { orientation on the } \\
\text { map based on clues } \\
\text { in an image. } \\
\text { (x,y) location, } \\
\text { accuracy of angle, } \\
\text { and task completion } \\
\text { time recorded. }\end{array}$ & $\begin{array}{l}\text { Environmental Location } \\
\text { Participants are asked to locate } \\
\text { themselves and the direction of } \\
\text { orientation five separate times } \\
\text { on a blank campus map during } \\
\text { a walk across campus. } \\
\text { (x,y) location, accuracy of } \\
\text { angle, and task completion time } \\
\text { recorded. }\end{array}$ & $\begin{array}{l}\text { Non-metric location coding } \\
- \\
\text { “Subjective” or egocentric } \\
\text { perspective. Piecemeal } \\
\text { updating of the } \\
\text { environmental frame of } \\
\text { reference based on vision. }\end{array}$ \\
\hline $\begin{array}{l}\text { Place } \\
\text { Recognition }\end{array}$ & $\begin{array}{l}\text { Photo Elicitation } \\
\text { Test } \\
\text { Participants create an } \\
\text { image sequence of } \\
\text { common landmarks } \\
\text { that would be } \\
\text { encountered on a } \\
\text { given route from a } \\
\text { pool of images. } \\
\text { Image identification, } \\
\text { sequence and task } \\
\text { completion time } \\
\text { recorded. }\end{array}$ & $\begin{array}{l}\text { Route Knowledge Test } \\
\text { Participants study a sequence of } \\
\text { four common campus } \\
\text { landmarks and are asked to } \\
\text { develop a route that will visit } \\
\text { each location. Participants are } \\
\text { asked at each location to } \\
\text { estimate the time to the next } \\
\text { location. } \\
\text { Route tracks, task completion } \\
\text { time and sequence of } \\
\text { landmarks are recorded. }\end{array}$ & $\begin{array}{l}\text { Route choice - } \\
\text { Homing - agents moving } \\
\text { along a direct path towards } \\
\text { target. } \\
\text { Path Integration - } \\
\text { continuous updating of } \\
\text { route based on } \\
\text { environmental cues. }\end{array}$ \\
\hline Route Planning & $\begin{array}{l}\text { Written Direction } \\
\text { Test }\end{array}$ & $\begin{array}{l}\text { Piloting Test } \\
\text { Participants are asked to }\end{array}$ & $\begin{array}{l}\text { Environmental knowledge } \\
\text { acquisition - agent ability }\end{array}$ \\
\hline
\end{tabular}




\begin{tabular}{|l|l|l|l|}
\hline & $\begin{array}{l}\text { Participants are asked } \\
\text { to write directions } \\
\text { from an origin to a } \\
\text { destination based on } \\
\text { information from a } \\
\text { map and as given to } \\
\text { someone without use } \\
\text { of the map. }\end{array}$ & $\begin{array}{l}\text { navigate from an origin to a } \\
\text { destination along a route where } \\
\text { each decision point represents } \\
\text { either a landmark-based } \\
\text { decision or network-based. } \\
\text { Route tracks and task } \\
\text { completion time are recorded. }\end{array}$ & $\begin{array}{l}\text { to integrate landmarks, } \\
\text { path network structures, } \\
\text { and spatial relationships } \\
\text { between places during } \\
\text { movement. }\end{array}$ \\
\end{tabular}

Table 2: Empirical Measures

From here, the model can work as a virtual laboratory in two distinct ways. First, different arrangements of cognitive abilities can be simulated and inferences made about how variations in any of the variables impacts individual behavior. For example, the variable spatial memory can be iteratively simulated at different values to understand how that individual skill impacts pedestrian behavior within the environment. Second, cognitive variables can be maintained constant to represent real-world individuals, and the environment iteratively changed to understand how subtle changes to the environment directly impact individual behaviors. In this second scenario, the real-world human impacts of structural changes to the environment, such as redevelopment of sidewalk conditions, street networks and public places, can be more thoroughly understood before construction. Figure 1 is a screen capture of the model interface, which includes agent parameter controls (on the left), the street grid environment (in the middle) and the model computational outputs (on the right). This work is currently being written up in two peer-reviewed articles for academic journals.

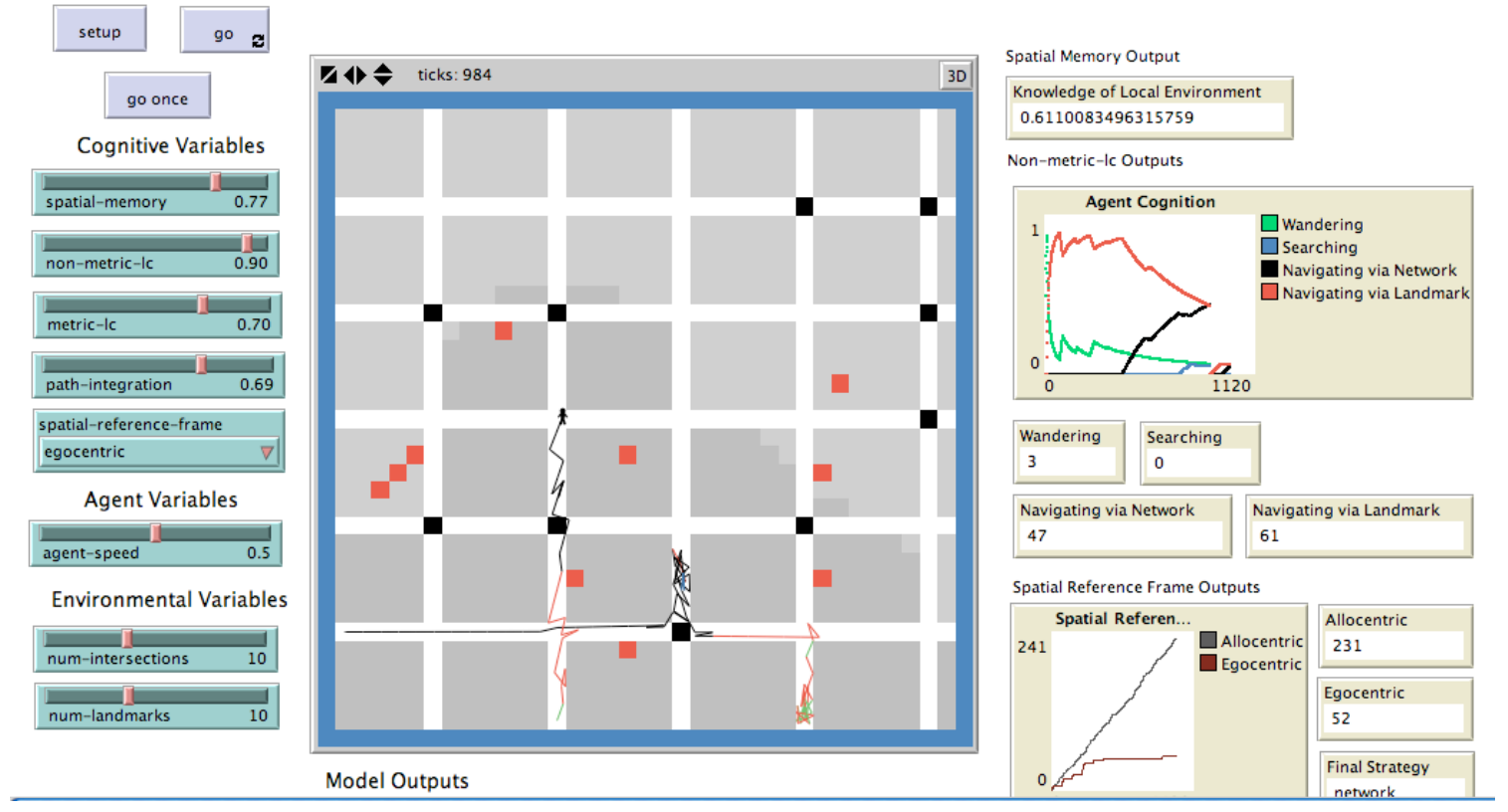

Figure 1: Example of model interface. 


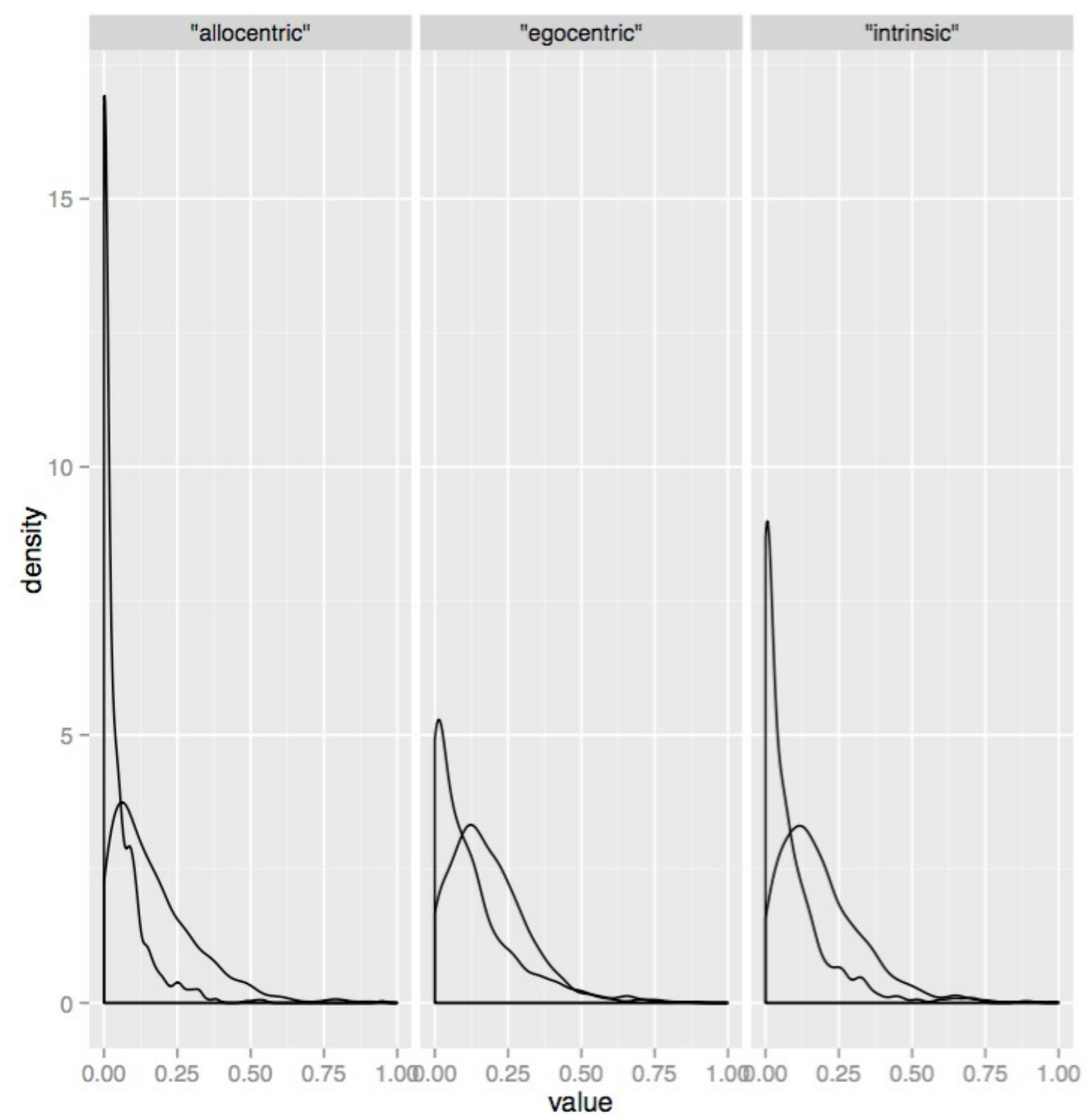

Graph of route-choice strategy for individuals based on route strategy (allocentric, egocentric or intrinsic) with frequency of usage for Cartesian/Cardinal or Topological/First Person language when giving directions.

A second model, while similar in structure to the cognitive model, focuses on the interactions between environmental features and physical disabilities of agents. Using survey data specifically asking about how different types of urban features either facilitates or hinders environmental accessibility for people who are blind, people who use powered wheelchairs, and people who use manual wheelchairs or other assistant walking devices. For example, the results of our survey reveal that sidewalk characteristics significantly affect travel behavior of people with disabilities. Figure 2 illustrates some of these characteristics, including: the presence/absence of a sidewalk, sidewalk condition and connectivity to marked intersections, as examples. The survey was designed with and administered by the Lane Independent Living Alliance (LILA), fostering collaboration between academic research and a local disability 
advocacy group. This model allows the user to assign the agent with one of the disabilities and records the agent interactions with the different types of urban features, creating a model output chronicling how accessible the environment is to different individuals. The accessibility of the model environment can be systematically changed to mimic different types of accessible redevelopment - such as audible crosswalks, textured curb cuts and sidewalk dimensions - to gain a greater understanding of how different types of accessible urban features influence realworld decision making and behaviors. The second model is in the development phase, with the ultimate goal of developing a deeper understanding of environmental accessibility and informing municipal redevelopment.
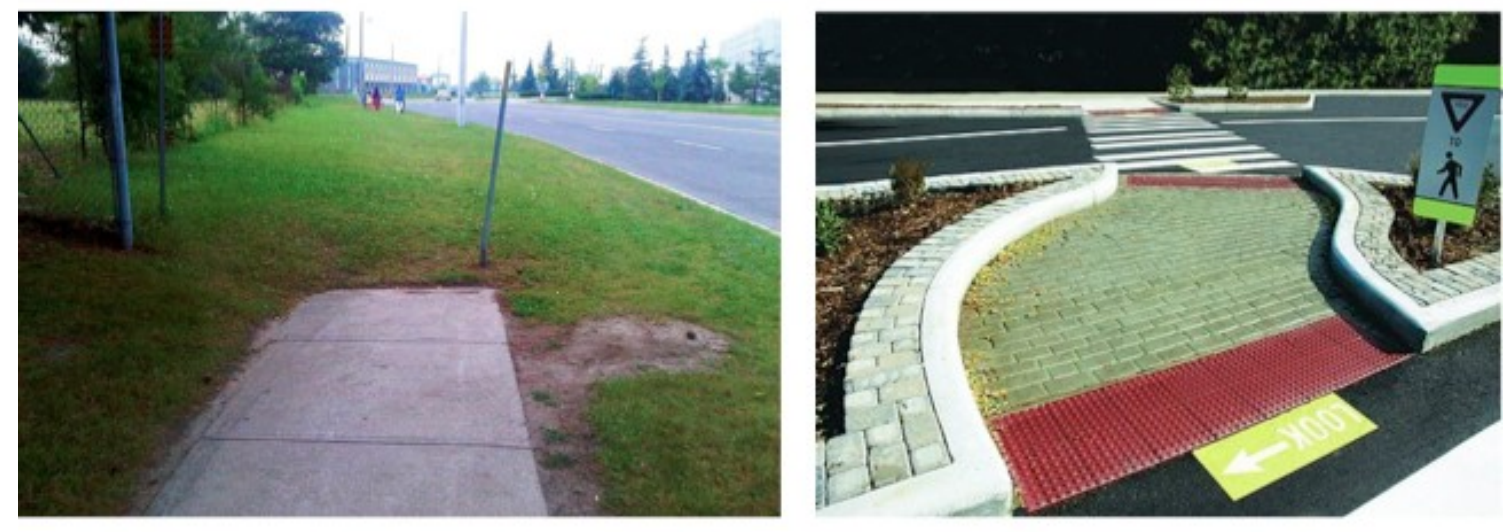

Figure 2: Examples of sidewalk characteristics.
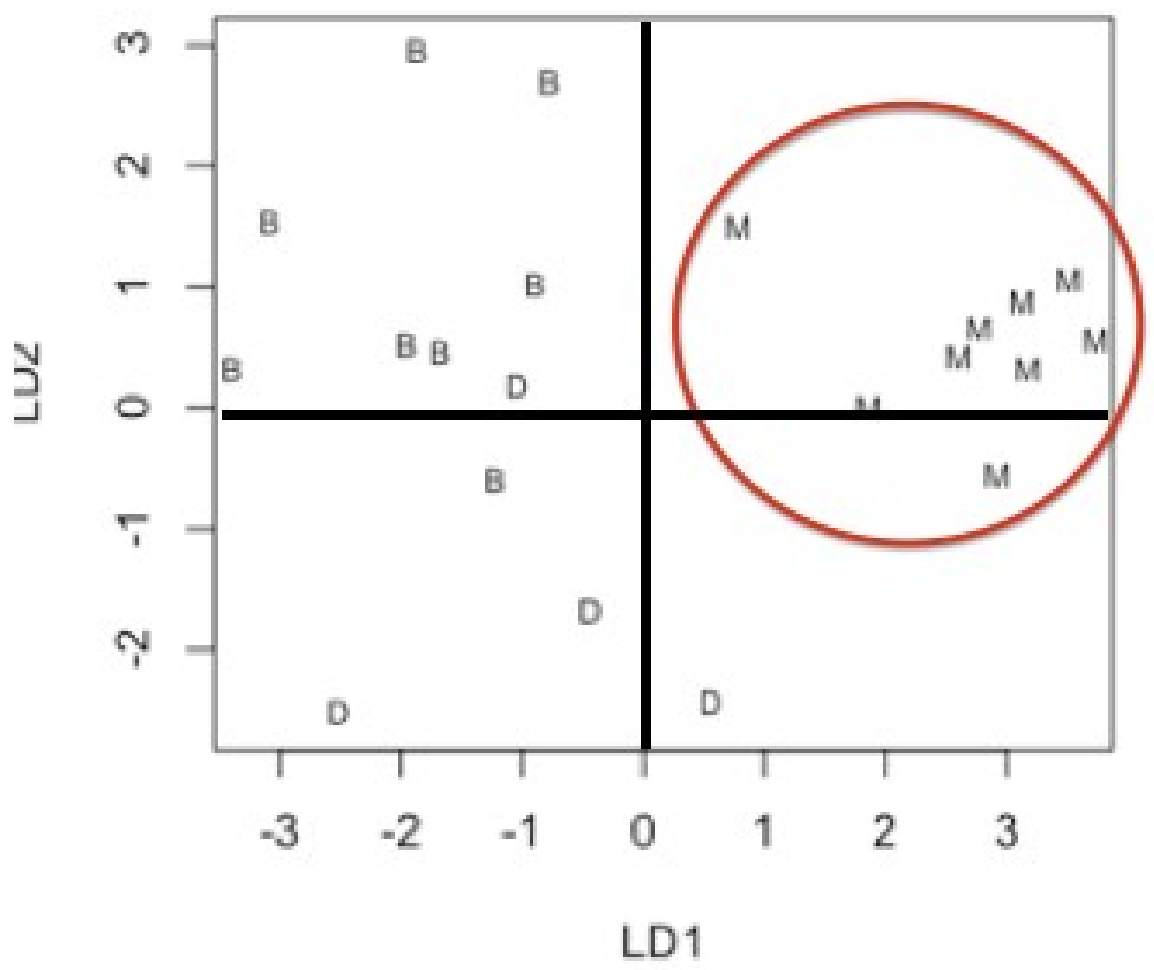
Linear Discriminate Analysis (LDA) for different disability groups interactions with environmental feature ground obstructions.

\subsection{CONCLUSION}

Both of the models developed in this project use a data-driven approach to parameterize the interactions between agents and the model environment to simulate human-urban interactions. The data-driven approach allows for a unique opportunity to make inferences on individual behavior within the urban system and gain greater insight into how redevelopment and changes to certain urban features could influence different populations. The environmental cognition model illustrates the importance of further consideration into the ways in which people perceive and cognitively encode the environment. The disability model highlights the often hidden and taken for granted elements of the cityspace and the influence of subtle design practices on people with disabilities.

The objectives of the project are aligned with the NITC Advisory Board Priority to understand the relationship between infrastructure and the effect on travel behavior. This project directly and meaningfully connects with three of the five stated NITC themes. The most substantive connection lies with the NITC theme goal to increase the efficiency and understanding of pedestrian travel. In fact, the primary motivator of this project was to examine the behavioral decisions behind travel, through an interdisciplinary approach that included: environmental perception, cognition, geographic information science, and modeling. A second NITC theme states an objective to make the best use of data, performance measures, analytical tools and new technologies. Specifically, that theme encourages projects that will lead development in multimodal performance metrics, data and tools that will allow decision makers to create more livable transportation. Our developed models directly address this theme by providing a cutting-edge interactive tool based on empirically gathered pedestrian choice measures. A third NITC theme focuses on health and safety while a stated NITC priority stresses the importance of considering the needs of changing demographics and an aging population. This theme and priority were a key focus of our research. Working with project partner Lane Independent Living Alliance (LILA), we recruited project participants with a variety of disabilities. People with disabilities often exclusively rely on pedestrian routes and mass transport. Any model of pedestrian travel behavior is incomplete without including this important group of pedestrians. 



\subsection{REFERENCES}

Abbas, M. Agent-Based Modeling and Simulation. Transportation Research Circular E-C168: Artificial Intelligence Applications to Critical Transportation Issues. Transportation Research Board of the National Academies. Washington DC. 2012.

Avineri, E. Travel Behavior Research. Transportation Research Circular E-C168: Artificial Intelligence Applications to Critical Transportation Issues. Transportation Research Board of the National Academies. Washington DC. 2012.

Avineri, E and JN Prashker.. Sensitivity to Travel Time Variability: Travelers’ Learning Perspective. Transportation Research Part C. 13(2): 157-183. 2005

Bernhardt, KLS. Agent-Based Modeling in Transportation. In Transportation Research Circular E-C113: Artificial Intelligence in Transportation: Information for Application. Transportation Research Board of the National Academies. Washington DC. P. 72-80. 2007.

Dia, H. An Agent-Based Approach to Modelling Driver Route Choice Behaviour Under the Influence of Real-Time Information. Transportation Research Part C. 10(5-6): 331-349. 2002.

Guo, L, S Huang, AW Sadek. A novel agent-based transportation model of a university campus with application to quantifying the environmental cost of parking search. Transportation Research Part A. 50: 86-104. 2013.

Montello, DR, KL Lovelace, RG Golledge, and CM Self. Sex-Related Differences and Similarities in Geographic and Environmental Spatial Abilities. Annals of the AAG. 89(3). 515534. 1999.

Morton, T and M Yousuf. Technological Innovations in Transportation for People with Disabilities, Workshop Summary Report, February 23, 2011. US Department of Transportation. 2011.

Shi, X, Y Xu, Y Xu, and J Song. A simulation Study of Agent-Network Based Route Guidance System. Proceedings of 2005 IEEE in Intelligent Transportation Systems. 2005.

Tilahun N, D Levinson. An Agent-Based Model of Origin Destination Estimation. The Journal of Transport and Land Use. 6(1): 73-88. 2013. 

Transportation Research and Education Center

Portland State University

1900 S.W. Fourth Ave., Suite 175

Portland, OR 97201 